\title{
Real Time Monitoring for the Most Vulnerable: Concepts and Methods
}

\author{
Henry Lucas, Martin Greeley and Keetie Roelen
}

Abstract In assessing the value of different approaches to real-time monitoring for the most vulnerable, an initial requirement is to set out a conceptual framework that provides at least some degree of clarity as to what precisely is meant by 'real time', 'monitoring' and 'vulnerable' - all terms that can be highly contextspecific. That is the first task addressed here. The second is to consider potential sources of data that might be used to undertake real-time monitoring and assess their advantages and disadvantages for the present purpose. Four general approaches are considered - community-based participatory monitoring, sentinel sites, routine data systems and rapid surveys - and selected examples from the literature are given to illustrate the potential use and limitations of their applications. ${ }^{1}$

\section{Framing the discussion}

Innovation in Information and Communication Technology (ICT) continues to accelerate and new opportunities to strengthen information systems through real-time data are being rapidly adopted across the globe. In health alone, a recent WHO survey found 835 health-related services using mobile phone technology. However, there has only been limited evaluation of projects and programmes and we are as yet low on the learning curve. For the present context, an important first step is to get clarification on what we mean when we talk about 'real-time monitoring for the most vulnerable'.

\subsection{Real-time information}

'Real-time information' seems to have a clear interpretation - current information available for instant response - such as a car dashboard provides a driver; we rarely need to react immediately to changes in economic and social data and can thus be more flexible, but how much more? There are two characteristics of most innovations promoting real-time monitoring of social indicators which together provide a practical definition. First, much discussion of realtime information implicitly assumes a central role for ICTs. There are obvious exceptions - for example, community-based monitoring of drugs at health clinics or teacher absenteeism at the local primary school is often 'current and immediate' but may only involve written records. Nevertheless, the current enthusiasm, and the funding, for real-time monitoring is clearly driven by the potential of ICTs.

Second, 'real time' is often defined in relation to existing systems of information collection and reporting; thus a quarterly sentinel site survey of child nutrition is considered 'real time' compared to traditional national nutrition surveys, typically conducted every few years. Note, however, that the provision of more timely information may involve increased frequency of data collection but may also be achieved via more frequent or faster reporting; using SMS texting to report community health data rather than having to post or physically deliver reports may not generate any new data but simply provides a faster way of getting existing data into use. Combining this observation with the above discussion would lead to the definition of 'real time' as: 'higher frequency data collection or reporting, often using ICTs'.

\subsection{Monitoring}

What constitutes higher frequency depends on context. One obvious distinction is that between data intended for use in service delivery and data intended to inform policy development. But even in the area of service delivery the required frequency may vary substantially. In the immediate aftermath of a disaster, information 
for emergency response teams will usually be required in hours, days or weeks in order to plan effective interventions. For other contexts, for example, monitoring HIV incidence or use of insecticide-treated bed nets for malaria prevention, six monthly data may be appropriate.

If appropriate frequency is determined by intended data use, it is evident that another core attribute of any real-time initiative should be an effective response mechanism. This should surely be the main driver of commitment to real-time data because the benefits of more timely information are only realised when it leads to better development outcomes. These outcomes can derive from two types of monitoring; the monitoring of supply constraints and bottle necks which affect access and use of critical services; and the monitoring of demand, the needs of the most vulnerable. In practice, technology-driven enthusiasm for innovation in data collection may outweigh the capacity of service delivery systems or policy processes to respond (though the availability of more timely data may itself encourage improvement).

A further complication is that monitoring of public programmes, even using participatory methods, is often understood in a rather passive sense checking that programmes are adhering to an agreed plan of action. The use of conventional management tools, including logical frameworks, has encouraged this style of thinking and bureaucratic hierarchy in the public sector often perpetuates it. Monitoring should be primarily seen not as a tool for management supervision but as a resource for managers to improve performance. This leads to the following working definition of real-time monitoring: 'higher frequency data collection or reporting, often using ICTs, to strengthen current programme performance or to inform policy and the practice (design, scale and scope) of future service delivery'.

A final word of caution is required. Timeliness is a very important dimension of data quality but it is by no means the only dimension. There is little point in improving the frequency with which data is made available if this leads to less relevant or (substantially) less reliable data. One lesson that the internet has taught is the risk of being overwhelmed by instant access to huge volumes of mostly irrelevant and unreliable information. Yet another important, but often overlooked, dimension is data analysis to package and present information in such a way that their implications for relevant policy or programmatic responses are easily understood. Such a lack of tailored analysis of the data collected is one of the main reasons why governments have so much data that are not fed into policy deliberations.

\subsection{Vulnerability and the most vulnerable}

In the development literature, vulnerability is a term that for a long time was widely used in tandem with poverty but without clear distinction. Over the last three decades, though, there has been a growing understanding of the distinct contribution that vulnerability analysis can make to our attempts at improving wellbeing. Several strands of vulnerability analysis derive from Sen's work on famines (Sen 1981). One key observation was that food shortage was not the underlying cause of many famines but that vulnerability to famine was due to the inability of households to convert assets, their labour and livestock, for example, into food adequacy because food had risen in price relative to those assets. Famine was a failure of exchange entitlement.

The livelihoods framework extended the analysis of assets introduced by Sen to include five asset classes including social capital (Chambers 1989; Swift 1989; Scoones 1998). Similarly, the food security literature, both through early warning systems and vulnerability mapping, built on this central role of assets in different ways. These approaches have been important in understanding vulnerability as a condition, but pay relatively little attention to actually measuring vulnerability outcomes (Alwang et al. 2001). Rather they focus on strengthening household resilience to shocks and the development of coping mechanisms (Sabates-Wheeler et al. 2010).

By contrast, mainstream economics has focused on a more precise definition of vulnerability and appropriate measurement procedures (Morduch 1994; Dercon 2006). There is widespread agreement on how, in principle, this should be done. Everyone is exposed to shocks but not everyone is vulnerable to unacceptable levels of wellbeing loss; many will have the means to ensure some form of consumption smoothing. The economists' approach assesses whether unacceptable wellbeing loss occurs by reference to a benchmark, typically an income level but possibly a nutritional standard or some other wellbeing 


\begin{tabular}{|c|c|c|c|}
\hline & Micro (idiosyncratic) & Meso & Macro (co-variant) \\
\hline Natural & & $\begin{array}{l}\text { Rainfall } \\
\text { Landslide } \\
\text { Volcanic eruption }\end{array}$ & $\begin{array}{l}\text { Earthquake } \\
\text { Floods } \\
\text { Drought } \\
\text { Strong winds }\end{array}$ \\
\hline Health & $\begin{array}{l}\text { Illness } \\
\text { Injury } \\
\text { Disability }\end{array}$ & Epidemic & \\
\hline Life-cycle & $\begin{array}{l}\text { Birth } \\
\text { Old age } \\
\text { Death }\end{array}$ & & \\
\hline Social & $\begin{array}{l}\text { Crime } \\
\text { Domestic violence }\end{array}$ & $\begin{array}{l}\text { Terrorism } \\
\text { Gangs }\end{array}$ & $\begin{array}{l}\text { Civil strife } \\
\text { War }\end{array}$ \\
\hline \multirow[t]{3}{*}{ Economic } & \multicolumn{2}{|c|}{$\begin{array}{l}\text { Unemployment } \\
\text { Harvest failure } \\
\text { Ethnic discrimination }\end{array}$} & Output collapse \\
\hline & Business failure & Riots & $\begin{array}{l}\text { BoP, financial or currency } \\
\text { collapse } \\
\text { Technology or ToT shocks }\end{array}$ \\
\hline & \multicolumn{3}{|c|}{ Resettlement } \\
\hline Political & & & $\begin{array}{l}\text { Potential default on social } \\
\text { programme }\end{array}$ \\
\hline Environmental & & $\begin{array}{l}\text { Pollution } \\
\text { Deforestation } \\
\text { Nuclear disaster }\end{array}$ & \\
\hline
\end{tabular}

BoP - balance of payments; ToT - terms of trade.

Source Adapted from Holzmann and Jørgensen (2000).

indicator. While this approach provides conceptual clarity, it has proved of limited practical value. The Table 1 lays out some of the most common sources of shocks. Most of these have not been analysed in the economists' framework because there is insufficient information on likelihood, sensitivity and resilience. As Dercon (2006) observes, economists have concentrated on the most measurable risks such as drought and on shorterterm policy choices, principally social protection measures such as safety nets, ${ }^{2}$ rather than addressing the underlying causes of vulnerability.

UNICEF has been a partner in the development of vulnerability analysis and led attempts to relate the outcomes of shocks to the wellbeing of children. It faces a significant challenge precisely because, as described above, vulnerability analysis has tended to focus on the most obvious, immediate or measurable shocks. The most vulnerable children are the main concern of its equity strategy yet their vulnerability may not be well captured by livelihood risk, which is the foundation of most current analysis. They may live in households which Davies (1996) describes as facing structural vulnerabilities such as ethnic discrimination, illness, isolation or being femaleheaded. These vulnerabilities often mean that they are already below wellbeing threshold levels (or at risk of being so) without fresh shocks. They are a similar category to households in chronic or permanent poverty. Real-time monitoring for the most vulnerable has to address their situation as well as that faced by those at risk of transitory, shock-induced poverty.

\section{Real-time monitoring methodologies 2.1 Community-based monitoring}

Community-based Participatory Research (CBPR) is: 'an approach towards building 
accountability that relies on civic engagement, that is, in which it is ordinary citizens and/or civil society organizations who participate directly or indirectly in exacting accountability' (Malena et al. 2004: 3). CBPR is a family of approaches and methods, through which 'people are facilitated to do things for themselves' (Chambers 2010: 19). Different traditions in CBPR espouse different views on how the democratisation of knowledge and information can lead to empowerment and better decision-making (Gaventa and Cornwall 2008). Common to most traditions is a focus on the everyday dimensions of experience, collaborative inquiry and capacity building (Chambers 1995). Numerous case studies have demonstrated the benefits of CBPR, which include:

- The emergence of new insights, priorities and definitions of problems and issues;

- The means to overcome the lack of conventionally available data;

- Timely and cost-effective data generation for guiding action and informing development interventions;

- Increased awareness and opportunities for advocacy through community ownership of the research process (Barahona and Levy 2002; Gillard et al. 2006; Park et al. 1993).

CBPR can be initiated by the state, civil society, NGOs or aid organisations. It may involve raising awareness about rights and making information about service delivery, progress on development projects, budgeting and spending accessible to citizens or it may rely on citizen-led information generation. It usually combines strategies for information collection and dissemination with processes that support public deliberation and collective action. It can be aimed at influencing donor policy, national policy or influence decisions made by local governments. It uses a wide and sometimes eclectic variety of strategies, tools and mechanisms for information collection, dissemination, analysis and deliberation (Chambers 2008).

CBPR has been applied in almost every domain of development and community action: from disaster management (Kennedy et al. 2008) and conflict resolution to slum development (Gillard et al. 2006; Wall 2006) and the establishment of the rights of indigenous people to nutrition, health awareness and action. However, some studies are beginning to question established assumptions that citizen-engagement and participatory research alone can achieve development outcomes. A recent review indicates that the evidence of impact in this field is mixed (McGee and Gaventa 2010) and argues that: 'much of the current evidence base relies on untested normative, positive assumptions and underspecified relationships between mechanisms and outcomes' (ibid.: 17). CBPR has become established practice in many organisations. Indeed, the incredible rise of participatory methodologies in the 1990s led to intense criticisms of the frequent abuse of participatory ideals and practices (Cornwall and Guijt 2004; Cooke and Cothari 2001). The key areas of concern were:

- the assumption that using PRA [Participatory Rural Appraisal] methods and/or approach in itself brings about positive change;

- lack of conceptual clarity, transparency and accountability;

- emphasis on information extraction with the rhetoric of political correctness;

- unchallenged assumptions of community harmony;

- lack of in-depth analysis which obscures awareness of political realities within communities;

- one-off training, with no follow-up by trainers or institutions;

- poor integration of PRA into project planning and implementation;

- lack of clarity about reasons for using PRA;

- agendas driven from outside the community, not from within; and

- co-option of the acronym, making it a label without substance (Guijt and Cornwall 1995: 1-2).

A variant of CBPR, community-based monitoring systems (CBMS), focuses on collecting data at the local level to inform policy and practice. CBMS originated in the Philippines in the 1990s with the aim of providing information on the impact of macroeconomic policies and structural adjustment programmes on households and individuals. The approach seeks to strengthen development planning by institutionalising data collection and validation for use primarily by local administrations (Reyes and Due 2009). Like other forms of participatory research, CBMS emphasises community participation in all 
aspects of the research cycle: from defining what data is captured, to analysing and validating the collected data, to using the data to influence policy.

In a review of experiences in the field, Reyes and Due identify the following practical lessons:

- Multilevel partnerships between researchers, government officials and communities were essential;

- Response rates were higher in cases where efforts were made to inform and enlist the support of the community before data collection started;

- Indicators and questionnaires needed to be simple and short. The information generated was more likely to be used by different levels of government if there were linkages between CBMS data and national indicators. The development of appropriate indicators was a research-intensive and time-consuming process;

- Support needed to be provided to local people with data collection and tabulation. Local communities were keen to develop their ability to analyse the data. The teams in charge of training almost always underestimated the time required for capacity building;

- To ensure the quality of the data and the collaboration of the households, the enumerators needed to be of different professions, ages and genders and from different socioeconomic groups;

- The design of the questionnaires has to take into account the capacities and knowledge level of the local population;

- Returning the data to all stakeholders was essential for strengthening the links between research and practice. Meetings, workshops, community scorecards and village books, CD-ROMS, newsletters and travelling caravans were used to present the results to communities. In a country with a high level of illiteracy, data were translated into local languages and drawings posted at village assembly offices;

- Computer processing of data worked well only in cases where local human, technical and financial capital already existed;

- Presentation of data in colour-coded maps was an extremely useful tool for communicating research findings to communities and decision-makers;
- The best results resulted from combining surveys with focus groups discussions to refine indicators, validate and interpret findings;

- The system's sustainability rested on political will at local and national levels.

New methods for data collection and analysis supported by information and communication technologies are fuelling innovation around the production, delivery and presentation of local information for and by vulnerable communities. Even programmes such as that on Communityled Total Sanitation (CLTS), an innovative grass roots methodology for mobilising communities to eliminate open defecation, is incorporating mobile phones to enable communities to monitor progress towards achieving this goal (Mukherjee et al. 2011).

\subsection{Sentinel site surveillance systems}

The term 'sentinel site surveillance' is generally used to denote the monitoring of selected communities or service delivery units (health facilities, schools, etc.). Where sites are related to a specific intervention, monitoring may be wide ranging, tracking changes over time in context, input, process, output and outcome indicators to assess the extent to which the intervention is being implemented as intended and having the expected effects. In other cases the range of monitoring variables may be much more limited. For example, the primary function of a demographic sentinel site surveillance system is to record vital events in order to determine trends in mortality and fertility. Other systems, for example those relating to notifiable diseases, medical conditions or malnutrition may be linked to specific response mechanisms involving action to treat either individuals or groups of individuals identified as at-risk.

The selection of communities will reflect the objectives of the system. In some cases the aim may be to select sites that are judged to be representative of larger populations and which can be used to generate regional or even national estimates. ${ }^{3}$ In other cases, the focus may be on communities that are particularly vulnerable, for example to food insecurity or specific diseases. One key issue is that over time the focus on the selected sites will tend to attract additional resources, possibly from external agencies seeking to undertake research or pilot initiatives, impacting on the characteristics which influenced their original selection. 
A potential weakness of sentinel site surveillance is that sites are often selected for study at least partly for reasons that substantially impact on the generalisability of findings. These reasons may include factors such as donor preferences, resource constraints, geographic location, infrastructure, and the degree of cooperation and commitment from local authorities and the general population. This implies a need to understand clearly that any findings cannot be generalised to populations outside the sites using the logic of statistical inference, which relies on the use of probability sampling. Claims that the sites are 'representative' of broader populations have to be rigorously examined.

Unfortunately, this is a requirement that is frequently ignored.

\subsubsection{Nutrition surveillance sites}

Sentinel site surveillance systems were seen as potentially one of the most effective mechanisms for assessment of the nutritional effects of the economic adjustment policies of the 1980s on poor and vulnerable groups (Shoham et al. 2001). However, a consensus gradually emerged that, while it was possible to generate reliable and relevant data from these sites, insufficient thought had been given to the development of systems that could make effective use of this data. While there was 'significant data collection, too few data were being compiled, fewer still were being communicated, and ultimately very few were used to improve nutrition related action' (Jonsson et al. 1998).

The type and frequency of data collection activities will vary substantially depending on the primary objective. In a context of relative stability, the aim may be to provide guidance on general policy concerns, for example strategic decisions relating to the agricultural sector or poverty reduction. In this case, data collection may involve a combination of routine data, for example clinic or community-based growth monitoring, and occasional large-scale surveys that allow detailed econometric analysis. At times of serious food shortages or in an emergency situation, where immediate action is required, the emphasis will be on gathering data that can provide rapid and where possible, frequently updated information that can inform relief agencies. In many cases the appropriate approach will be to design systems that have an inbuilt capacity for adaption to deal with emergency situations should the need arise.

The Malawi Integrated Nutrition and Food Security Surveillance System (MINFSSS) has been functioning since 2003 under a partnership between Action Against Hunger and the Malawi ministries of Health and Agriculture. Intending to inform timely response to changing trends in malnutrition and household food insecurity, the surveillance system monitors trends in nutritional status of a potential number of 9,100 children (350 per district) from five growth monitoring clinics (GMCs) in each of the 26 districts in Malawi except for Likoma. These children are randomly selected from a population of children attending the GMC (and thus include healthy, malnourished, and sick children). Out of the 9,100 children, 1,300 children (50 per district) are selected for household food security information. These same children are followed for over a period of a year. Each GMC was randomly selected on the basis of their representative nature for the district. An evaluation commissioned by the FAO (Teller 2008) found that the surveillance system has been functioning vertically and often perceived as a 'donor' programme, without local ownership and capacity, with little timely use of the information except seasonally and mainly at the national level.

Among data quality issues, a sampling bias was found in the older ages of the sentinel under-fives children. The main recommendation is to continue the sentinel approach to monitor change under a surveillance system, but to improve the system in response to district stakeholder requests. Specific improvements suggested were to increase the number of sentinel sites for a more representative sample in each district and to make technical improvements concerning the quality of the panel data collection, both in anthropometry and food insecurity, and the yearly re-sampling and monthly replacement sampling methods.

\subsubsection{Facility-based sentinel site surveillance systems}

In recent years, partly in response to the substantially increased funding available to agencies combating selected diseases (in particular HIV/AIDS, malaria and TB), there has been increasing use of health facility-based sentinel site surveillance systems, typically combined with interventions to provide improved case management. A recently established system in 
Vietnam focuses on 'active pharmacovigilance', the close monitoring of anti-retroviral treatment (ART) of AIDS in sentinel site facilities in order to identify issues relating either to the drug delivery system or drug safety and efficacy, or 'to understand better the benefits and risks of medicines under conditions of actual use' (Management Sciences for Health 2010: 6). Because the aim is primarily to guide policy on the use of ARTs, selection of facilities was primarily based on their ability to meet the demanding data collection requirements, not on the basis of their representativeness. In Uganda, a malaria sentinel surveillance site system was established in six facilities, each in a different health district, with the primary aim of estimating trends in malaria morbidity rates (Sserwanga et al. 2011). In each facility an intervention was undertaken to improve case management, primarily through the appropriate use of diagnostic tests.

\subsubsection{Health and demographic surveillance systems}

The INDEPTH network ${ }^{4}$ has 42 members who oversee health and demographic surveillance system sites in 19 countries (Sankoh and Binka 2005). Most were originally established to undertake longitudinal demographic surveillance, essentially providing reliable fertility and mortality indicators that could be used in population forecasts. It should be noted that the interest in this area by international donors was a major factor in providing substantial investment in financial and human resources, training, and logistical coordination required to start up and maintain sites. While sentinel surveillance data collection can be relatively inexpensive once reliable systems are in place, building and sustaining those systems requires a major commitment.

The sites have been seen by many observers as one of the most promising approaches to the generation of reliable social data in countries with failing routine data systems: 'accurate and comprehensive monitoring programmes tailored to specific system contexts must be set up, preferably based on demographic surveillance systems such as those of the INDEPTH network' (Hutton and Tanner 2004: 893). In practice, they have been extensively used to study long-term influences on morbidity and mortality (e.g. Chowdhury et al. 2010; Breiman et al. 2004) and the impact of specific interventions (e.g. Alba $e t$ al. 2011; Schellenberg et al. 2004). However, those managing such sites have also developed a strong sense of responsibility for the wellbeing of 'their' populations and this is often reflected in the provision of services, especially health services, in these areas. The impact of the HIV/AIDS epidemic strongly reinforced the need for site managers to be more than external observers and to promote services for those affected.

\subsection{Routine data systems}

Routine data systems (RDS) should be a primary source of timely information. They can be relatively inexpensive and generate time-series data that allow far more persuasive analysis and interpretation than intermittent cross-sectional surveys. Perhaps most importantly, they can permit a degree of disaggregation that has the potential to allow users to determine not just that there are problems with service delivery in a given sector but precisely where provision is failing and which sections of the population (women, the elderly, particular ethnic groups, etc.) are likely to be suffering the greatest impact.

In most countries routine data scarcity is not a problem. The major constraints on effective use relate to the poor quality of that data, its limited content and coverage, and the lack of compatibility between the various sources. If these constraints could be overcome, the benefits would be considerable. However, there has been a long-standing reluctance on the part of both national governments and international agencies to commit the substantial, long-term resources that would be required to overcome what are seen as deeply entrenched and intractable institutional barriers to sustainable improvement. By comparison, funding a sample survey or establishing a standalone project monitoring system has proved much more attractive. One consequence has been that in most countries there is a multiplicity of information systems, often linked to existing or erstwhile vertical programmes, with no incentives to encourage integration, rationalisation or continuity.

Over the last decade, at least three major international organisations have taken up the challenge. The General Data Dissemination System $^{5}$ was set up by the IMF to improve the quality of economic and financial statistics but has since extended its remit to include social 
statistics. The Partnership in Statistics for Development in the 21 st Century ${ }^{6}$ provides support to national statistics offices, addressing both RDS and surveys (2010), while the Routine Health Information Network ${ }^{7}$ promotes innovations specifically in the area of health RDS.

\subsubsection{Education management information systems}

Booth and Lucas (2004) discuss an innovative approach to education management information systems (EMIS) in the Gambia. Rather than attempting to improve reporting from the local level to the centre, priority was given to disseminating to all district offices a computer disc containing whatever reasonably reliable and relevant information was already available, adding a number of 'league tables' to show how districts compared on key performance indicators. As expected, many district officials were shocked to find themselves at the bottom of these tables because they had failed to provide the data on which they were based. While complaining (often in a fairly aggressive manner) at the unjust impression created by these tables, they very rapidly compiled and submitted the missing information. However, as with many such initiatives, this initial success proved unsustainable once the consultants leading the EMIS process left the country and the system gradually deteriorated over time (Sander et al. 2005).

There have been a variety of studies exploring the use of mobile technology to support EMIS. ${ }^{8}$ The UK DFID funded a project in Kenya which included an examination of the possibilities for using SMS for the majority of routine statistical returns from schools. Under this scheme, head teachers in each school used a mobile phone to send a standard format message each week, giving data such as pupil numbers by age and gender, to a specified telephone number. An initial study indicated that this approach would be viable (Traxler and Dearden 2005). The University of Jyväskylä in Finland conducted a pilot study on the use of mobile phones to collect EMIS school-based data in Ghana. ${ }^{9}$ This study, in the Ashanti region, involved 35 head teachers and 21 education statisticians in two districts. Again, an initial assessment was said to be favourable in terms of cost, reliability and timeliness.

In 2010 the Agile Learning Company ${ }^{10}$ was contracted by the Ministry of Education and
Sports in Uganda to design and implement a decentralised national EMIS covering 98 districts. The project includes the piloting of a school-based EMIS application in selected schools to explore its potential to improve management and link critical school data directly into the national EMIS-GIS. The Ministry of Education in Rwanda had contracted the same company in 2009 to develop a similar solution for both schools and universities. This followed a contract with the Rwanda National Examinations Council to develop a registration and SMS-based online results management information system, allowing students to directly access a database to see their examination results. A similar initiative is being piloted in Kenya, Mauritius, Botswana and Swaziland using a variety of local mobile service providers.

The Netherlands Development Organisation is supporting a pilot study by the Makerere University Faculty of Computing and IT, which involves 50 schools in each of two districts, Mbale and Kiboga. ${ }^{11}$ In 2010 the schools were provided with Nokia phones which they will use to record attendance data using the OpenXdata software. The system will cover both pupils and teachers. A baseline survey suggested that some 12 billion Uganda shillings are paid each year to absent teachers. The new system is intended to allow weekly, as opposed to the current monthly, data collection. Another pilot study in Tanzania (Dias et al. 2010) used Open Source software and SMS to allow social workers to provide timely and reliable data on school-age orphans and other vulnerable children to government officials.

\subsubsection{Health Management Information Systems (HMISs)}

It is generally accepted that the development of reliable and effective health RDS is perhaps the most difficult challenge faced by those attempting to improve local and national health information systems in resource-poor environments. Even a very basic HMIS has to deal with the multiple combinations of symptoms, diagnoses and treatments that may be associated with the individuals who present each day at a diverse range of health facilities; the various drugs and other materials used in those treatments; the activities of diverse health workers employed by each facility; and typically the financial transactions associated with each patient encounter. A relatively recent article argues that one serious impediment to the 
development of effective HMIS is the absence of any systematic framework for their design and evaluation (Aqil et al. 2009) This has led to a situation in which there has seldom been any serious assessment of the performance or valuefor-money of such systems, even though they require substantial resources to establish and maintain.

The article reinforces an earlier observation by one of its authors that: 'One of the more consistent findings of these experiences is that decentralization of information management toward the district level is an effective strategy to improve routine information systems' (Lippeveld 2001: 13). The District Health Information System (DHIS) in South Africa seems to provide an apparently successful application of this approach. This originated from the universities of Cape Town and the Western Cape in collaboration with the University of Oslo. It was initially piloted in one district in Eastern Cape Province as part of the EQUITY project. ${ }^{12} \mathrm{~A}$ driving principle was the desire to simplify and integrate reporting requirements to enable the generation of a coherent system of indicators - known as the 'essential dataset'. Rather than allow vertical programme managers to specify these requirements, they were driven by detailed consultation with facility staff. 'For each data element... they had to answer the questions: Why do we want to collect this information? How will we use it?... If the health workers could not come up with a reasonable answer to either of the questions, the data element was discarded or reformulated' (Shaw 2005: 633).

While seen as a considerable advance on the previous RDS, the DHIS struggled to overcome the existing culture of health workers, who still tended to see the collection of data as a burden which took valuable time from their primary function of providing care. A detailed evaluation in ten primary health care clinics in KwaZuluNatal found that: 'There were encouraging gains in information collection at the primary care level; standard data items were collected with generally high reliability and timeliness.

However, data quality was poor and staff were unable to make effective use of it' (Garrib et al. 2008: 551). These issues have been addressed to some extent over recent years. The underlying database has been linked to a variety of validation, analysis and presentation packages that provide at least the potential for quality control and rapid feedback to health providers and managers. ${ }^{13}$ It is currently implemented in nine countries in Africa, in India, Vietnam and Myanmar ${ }^{14}$ and there are also pilot studies in Bangladesh and Sri Lanka. ${ }^{15}$

In terms of national-level HMIS, one key player is Voxiva, which has pioneered the use of information systems that can be accessed either via the internet or mobile and fixed line telephones. It has been involved in establishing a number of health networks including TRACnet, ${ }^{16}$ an integrated system for the collection and management of patient, drug and programme data for HIV/AIDS prevention and treatment in Rwanda. The system was introduced in 2004 and is currently employed in all 225 health facilities supplying anti-retroviral therapy. Almost 90 per cent of users access the system via a toll-free mobile or fixed line telephone interface. Other projects have included the Health Watch disease surveillance project in Tamil Nadu, ${ }^{17}$ which was set up following the tsunami disaster in 2004, and a system whereby rural health care providers use mobile telephones to provide routine assessment data on high-risk pregnancies to centrally based senior staff in the Ucayali region of Peru. ${ }^{18}$ The mobile telephone giant, Nokia, has recently entered into a partnership with the Brazilian government to provide a similar mobile phone-based network for community health workers providing services to the indigenous population. Funded by the UN Foundation and the Clinton Global Initiative, the MobiSUS project $^{19}$ aims to provide a system for collecting and disseminating health information from some of the most remote areas.

\subsubsection{Water supply}

An interesting recent application of SMS to monitor water supply systems has been implemented under an initiative called NextDrop,$^{20}$ developed at the University of California. The problem addressed was that even where households are provided with access to piped water on a rotational schedule, the supply is often highly erratic, usually as a consequence of technical failures but sometimes a reflection of corrupt behaviour by those responsible for distribution of what in many areas is a scarce and therefore valuable resource. 
Initial trials of the system began in the city of Hubli in the Indian state of Karnataka in 2010, funded by a grant from the Bill \& Melinda Gates Foundation and with the collaboration of the local water authority. Those responsible for opening the supply valve call an interactive voice response system which then sends SMS messages to consumers indicating when water should reach them, usually with 30-60 minutes' advance warning. Water engineers managing the supply facility are also provided with a real-time map of the city showing which valves are open. They are also directly notified of any departures from the designated rotation schedule. The interactive voice system then contacts a random sample of households to determine if they have received water. Conflicts between data provided by those responsible for valve opening and the household reports are used to alert the engineers.

\subsection{Surveys}

Household surveys play a central role in UNICEF's monitoring and evaluation efforts across its various programmatic areas. In response to the lack of data on particular intervention areas for children, UNICEF developed and set up its own survey, the Multiple Indicator Cluster Survey (MICS) in the mid1990s. Previously, internationally comparable survey data on issues concerning health and nutrition in developing countries, particularly for mothers and children, was only available from the Demographic and Health Surveys (DHS) that started in the mid-1980s (MEASURE DHS 2011; Alkire and Roche 2011). The MICS is essentially a survey tool that is provided to countries which want to fill data gaps. The implementer is the government and the MICS programme provides technical support. Thus the surveys are national, but the adoption of a standardised questionnaire makes it possible to draw cross-country comparisons.

Three additional rounds of the MICS have been conducted around the world. The second took place in 2000 in 65 countries, the third in 2005/06 in 50 countries and the fourth is currently under way (UNICEF 2011). The additional waves of data collection led to a considerable extension of the evidence base on children's outcomes as information was now available over time and could be referenced against baseline values. As such, MICS has been a crucial source of information for UNICEF and beyond.
Large-scale surveys are an important source of data for tracking social outcomes over time, considering disparities between different groups and evaluating policy or programme impacts. Advantages of this type of data include its representativeness (often national), wide range of information and ability to relate data on welfare outcomes to demographic and social characteristics. However, a big disadvantage is that they are relatively ill-equipped to capture rapid change. They are typically conducted every three to five years; involve long questionnaires that are time-consuming and expensive to complete; and are often subject to lengthy delays relating to data entry, cleaning and analysis. In terms of real-time monitoring and gaining immediate insight into rapid economic, societal and environmental changes and their impacts, large-scale standardised surveys in their present form do not appear an appropriate option, although innovations are emerging in MICS type surveys with higher frequency and possibly at smaller scale.

\subsubsection{Rapid surveys}

The 'rapid survey' concept is often dated to the WHO ' 30 by 7 ' cluster surveys that were introduced in 1978 to obtain rapid, inexpensive but reasonably reliable estimates of child immunisation coverage (Lemeshow and Robinson 1985). The designation relates to their sampling procedures. The target population is subdivided into non-overlapping 'clusters', usually defined by geographic boundaries. A sample of 30 clusters is taken with probability proportion to size (PPS) and then a quasirandom sample of seven households with children in the relevant age range is selected within each cluster. Following this procedure, coverage estimates can be obtained that can be confidently assumed to be within \pm 10 per cent of the true value. An equally important characteristic of these surveys is the insistence on brevity and simplicity. The basic survey instrument records simply the cluster location, the age and sex of the selected child and his/her immunisation status.

The original ' 30 by 7' design has proved very successful for the estimation of immunisation coverage at district level. However, its popularity, arising primarily from the low cost and ease of implementation, has resulted in the widespread use of the approach in many other areas, 
including disease prevalence, health-related knowledge and practices, and utilisation of health services. A similar approach has been adopted in Rapid Nutrition Surveys, which have often been undertaken in emergency situations (Prudhon and Spiegel 2007). In this case it is usually recommended that the second stage sample size should be increased to 30 children (SMART 2005).

The approach has attracted criticism. Turner $e t$ al. (1996) focus on the lack of formal probability sampling within clusters. For example, one popular technique involves selecting a random direction from a central location, listing all households along the chosen direction, selecting one at random and then visiting that household and its nearest neighbours until the required seven children have been enumerated. None of the commonly used methods meets the basic requirement of probability sampling, that every eligible member of the target population has a known, non-zero probability of selection. Simulation exercises suggest that the risk of sampling bias is substantially higher than in conventional cluster sampling. The paper suggests that a relatively simple modification can retain the advantages of the ' 30 by 7 ' design while ensuring a true probability sample. This involves: the production of a simple sketch-map of each selected cluster; dividing this into segments of roughly equal size; selecting one segment at random; and interviewing all eligible members of the target population in that segment.

Myatt et al. (2005) argue that while the PPS approach used in the ' 30 by 7' surveys may result in improved estimates overall, the associated tendency to sample areas of high population density may lead to a judgement that reasonable coverage has been achieved even where more remote, low-density areas have been severely neglected. This is of special concern in the case of feeding programmes, where a priority objective may be to identify such areas before children become severely malnourished. They describe an alternative approach, 'quadrat sampling', which was first adopted in 2002 for a district-wide feeding programme in the Mchinji district of Malawi. A $10 \mathrm{~km}$ by $10 \mathrm{~km}$ grid was overlaid on a map of the district. All those squares (quadrats) with more than 50 per cent of their area within the district were sampled.
Communities nearest the centre of each quadrat were then sampled, with sample size determined as the number that could reasonably be surveyed in a single day. All children in a community were screened to identify those suffering from malnutrition. Coverage in each quadrat was calculated as the proportion of malnourished children included in the feeding programme and overall coverage estimated by treating the quadrats as a stratum in a stratified sample. The survey was described as simple, inexpensive and rapid, providing results within just ten days.

Another alternative procedure, Lot Quality Assurance Sampling (LQAS) has been used to monitor vaccination coverage (Hoshaw-Woodard 2001; Deitchler et al. 2007), typically with the primary objective of identifying facilities failing to meet acceptable coverage levels. LQAS was developed for quality control purposes in the manufacturing industry. A 'lot' is a batch of manufactured items. The entire batch will be rejected as sub-standard if the number of defective items identified in a sample of a given size exceeds a critical value. The manufacturer has to decide the appropriate levels of two districts' types of 'risk': the (type one) risk of incorrectly accepting a 'bad' lot and the (type two) risk of incorrectly rejecting a 'good' lot. Adopting this approach, a district health manager would set the minimum acceptable level of immunisation coverage to be achieved by facilities. Each facility would then take a sample of children from its catchment population and if the number of non-immunised children in the sample exceeded a critical value their performance would be deemed unacceptable. The sample size and critical value would be determined by assumptions relating to type one and type two risks and an estimate of the true coverage rate.

As with the ' 30 by 7' surveys, the ease with which LQAS surveys can be implemented and their relatively low cost has encouraged wide application. A very favourable review (Robertson et al. 2006) identified some 640 LQAS surveys in 55 countries over the period 2000-04. Apart from immunisation, the topics included HIV/AIDS/ sexually transmitted infections, post-disaster assessment, women's health, growth and nutrition, diarrheal disease control, and quality management. On the other hand, a recent article (Rhoda et al. 2010), while endorsing what 
they describe as LQAS surveys based on 'sound statistical principles' (p60), warn that they can be used, either by design or lack of understanding, to produce findings which are misleading and potentially damaging to vulnerable populations, especially where they are linked to resource allocation.

The problem identified in this paper essentially concerns the inappropriate designation of type one and type two errors. Traditionally in statistical analysis, when we investigate a relationship we require strong evidence to overturn the 'null hypothesis' - that that relationship does not exist. This is equivalent to setting a low value for type one risk (typically 5 per cent, i.e. one chance in 20 of wrongly rejecting the null hypothesis). A number of LQAS exercises identified by Rhoda et al. (2010) inappropriately demanded a similarly high level of evidence to demonstrate failure. In the case of immunisation, one consequence may be that a facility with apparently low coverage is deemed to have demonstrated acceptable performance because the allowed 'margin of error' is very wide, i.e. it has to exhibit very poor performance to be declared unacceptable. If remedial action is then restricted only to these facilities, vulnerable children in areas which are also very badly served may suffer.

One widely used general purpose 'rapid' survey is the Core Welfare Indictor Questionnaire (CWIQ) survey, ${ }^{21}$ which was developed by the World Bank, UNICEF and UNDP to monitor human development indicators on access, utilisation and satisfaction with social services. It was designed to provide a means by which Poverty Reduction Strategy indicators could be estimated annually on a sufficiently large sample of households to allow for disaggregation by at least region, gender and age. It was seen as an alternative to the incomplete and unreliable estimates obtainable from administrative data systems. Because of the simple structure, standard questions set and machine-readable format, the time required for data processing and analysis should be two to three months from the start of fieldwork. The surveys were adopted by more than 20 countries, mainly in Africa (e.g. Ghana, Guinea, Malawi, Mali, Rwanda, Senegal and Sierra Leone).
2.4.2 Possibilities arising from the use of new technology With the astonishingly rapid growth in the ownership of mobile phones and the extension of GSM services to ever more remote areas, attention has shifted to exploration of the possibilities for collection of both survey and routine data using mobile devices. A relatively recent study (Seebregts et al. 2009), describe the development of survey software for the Palm ${ }^{\mathrm{TM}}$ Pilot PDA/Smartphone. This study found that: academics and officials with no particular programming skills could develop applications for surveys and routine returns using this software; that the mobile devices proved reliable in field use for extended periods; that the resultant data could be easily compiled in a form that facilitated analysis; and that capital costs were relatively limited if the equipment were used to undertake repeated studies.

For comparison is it interesting to consider another South African study, in this case using less expensive mobile phones. It involved a sample survey of almost 40,000 households in a peri-urban settlement near Durban (Tomlinson et al. 2009). The survey questionnaires were developed using a word processor and then wirelessly downloaded to Java-enabled mobile phones, using a proprietary web application called Mobile Researcher. ${ }^{22}$ The downloaded versions were complete with automatic data checking procedures and available in the multiple languages required for the diverse ethnic groups living in the area. The survey was undertaken by a team of 24 local Community Health Workers (CHWs), who received just two days' training. They had no previous experience of data collection but were familiar with SMS. Completed surveys were uploaded in encrypted form when network coverage was available. One advantage of this approach was that real-time supervision of the CHWs was possible. Work-rates could be monitored and excessively short interview times (possibly indicating data fabrication) recorded and followed up. When out of network range up to 50 completed surveys could be held on each phone. The authors found that the mobile phones were very reliable and significantly less prone to data transfer problems than the PDAs with which they had previous experience. They also saw the comparatively low value of the phones as a considerable advantage in areas of relatively high criminal activity. 


\section{Notes}

1 This article is an edited extract from the Desk Review commissioned by UNICEF on Real Time Monitoring for the Most Vulnerable implemented by the Institute of Development Studies (IDS) as part of UNICEF's global study on Real Time Monitoring for the Most Vulnerable (RTMMV). The Desk Review is based on secondary, publicly available literature and its selection of the country examples is illustrative rather than comprehensive.

2 The 2000-2001 World Development Report, focused on poverty, privileged the notion of security, the opposite of vulnerability. This gave impetus to the development of policy instruments, notably social protection, as a means of risk management.

3 The use of sentinel sites to generate such estimates can be highly contentious, perhaps most obviously in the case of the estimation of HIV/AIDS prevalence from antenatal clinic data (Brookmeyer 2010).

4 www.indepth-network.org/ (accessed 13 January 2013).

5 http://dsbb.imf.org/Pages/GDDS/ WhatIsGDDS.aspx (accessed 13 January 2013).

6 www.paris21.org (accessed 13 January 2013).

7 http://rhinonet.org/ (accessed 13 January 2013).

8 https://edutechdebate.org/educationmanagement-information-systems/emisopportunities-and-challenges-for-mobile-data-

\section{References}

Alba, Sandra; Hetzel, Manuel W.; Nathan, Rose; Alexander, Mathew and Lengeler, Christian (2011) 'Assessing the Impact of Malaria Interventions on Morbidity through a Community-based Surveillance System', International Journal of Epidemiology 40.2: 405-16, http://ije.oxfordjournals.org/content/40/2/405. full.pdf (accessed 13 January 2013)

Alkire, S. and Roche, J.M. (2011) Beyond Headcount: Measures that Reflect the Breadth and Components of Child Poverty, OPHI Working Paper 45, Oxford: Oxford Poverty \& Human Development Initiative (OPHI)

Alwang, Jeffrey; Siegel, Paul B. and Jørgensen, Steen L. (2001) Vulnerability: A View from Different Disciplines, Washington DC: Social Protection Unit, Human Development Network, World Bank

Aqil, Anwer; Lippeveld, Theo and Hozumi, Dairiku (2009) 'PRISM Framework: A Paradigm Shift for Designing, Strengthening collection-and-dissemination/ (accessed 13 January 2013).

9 www.mobiles4dev.com (accessed 13 January 2013).

10 www.agilelearning.com/Company.aspx (accessed 13 January 2013).

11 http://cit.mak.ac.ug/news-updates/308-cocisproject-impresses-president-museveni-.html (accessed 27 January 2013).

12 www.msh.org/global-presence/equity.cfm (accessed 13 January 2013).

13 www.dhis2.org/ (accessed 13 January 2013).

14 www.hisp.org (accessed 13 January 2013).

15 http://hispindia.org/index.php?option $=\mathrm{com}$ content $\&$ view $=$ article $\&$ id $=25 \&$ Itemid $=26$ (accessed 13 January 2013).

16 www.pepfar.gov/press/84654.htm (accessed 27 January 2013).

17 www.healthunbound.org/content/tamil-naduhealth-watch-0 (accessed 27 January 2013).

$18 \mathrm{http}: / /$ healthmarketinnovations.org/ program/nacer (accessed 27 January 2013).

19 www.clintonglobalinitiative.org/ commitments/commitments_search.asp? Section $=$ Commitments\&PageTitle $=$ Browse $\%$ 20and\%20Search\%20Commitments (accessed 13 January 2013).

20 http://nextdrop.org/ (accessed 13 January 2013).

21 http://go.worldbank.org/66ELZUGJ30 (accessed 13 January 2013).

22 Which was to become Open Source.

and Evaluating Routine Health Information Systems', Health Policy and Planning 24.3: 217-28 Barahona, C. and Levy, S. (2002) How to Generate Statistics and Influence Policy using Participatory Methods in Research, University of Reading, www.reading.ac.uk/ssc/n/SADC\%20DVD/ 02\%20Intermediate\%20Level/Module\%20I1/ Module\%20I1\%20Session\%2014-16/How_to_ generate_stats_and_influence_policy.pdf (accessed February 2013)

Booth, David and Lucas, Henry (2004)

'Monitoring Progress towards the Millennium Development Goals at Country Level', in Richard Black and Howard White (eds), Targeting Development: Critical Perspectives on the Millennium Development Goals and International Development Targets, Oxford: Routledge

Breiman, Robert F.; Streatfield, Peter Kim; Phelan, Maureen; Shifa, Naima; Rashid, Mamunur and Yunus, Mohammed (2004) 'Effect of Infant Immunisation on Childhood Mortality in Rural Bangladesh: Analysis of 
Health and Demographic Surveillance Data', The Lancet 364: 2204-1 1

Brookmeyer, Ron (2010) 'Measuring the HIV/AIDS Epidemic: Approaches and Challenges', Epidemiologic Reviews 32: 26-37, http://epirev.oxfordjournals.org/content/32/1/ 26.full.pdf (accessed 13 January 2013)

Chambers, R. (2010) Paradigms, Poverty and Adaptive Pluralism, IDS Working Paper 344, Brighton: IDS

Chambers, R. (2008) Revolutions in Development Enquiry, London: Earthscan

Chambers, R. (1995) 'Poverty and Livelihoods: Whose Reality Counts', Environment and Urbanization 7.1: 173-204

Chambers, R. (1989) 'Editorial Introduction: Vulnerability, Coping and Policy', IDS Bulletin 20.2: 1-7

Chowdhury, Hafizur Rahman; Thompson, Sandra; Ali, Mohammed; Alam, Nurul; Yunus, Md. and Streatfield, Peter Kim (2010) 'Causes of Neonatal Deaths in a Rural Subdistrict of Bangladesh: Implications for Intervention', Journal of Health, Population and Nutrition 28.4: 375-82, www.jhpn.net/index.php/jhpn/article/ view/411/405 (accessed 13 January 2013)

Cooke, B. and Cothari, U. (eds) (2001) Participation: The New Tyranny?, London: Zed Books

Cornwall, A. and Guijt, I. (2004) 'Shifting Perceptions, Changing Practices in PRA: From Infinite Innovation to the Quest for Quality', Participatory Learning and Action 50: 160-7

Davies, S. (1996) Adaptable Livelihoods, New York: St Martin's Press

Deitchler, Megan; Valadez, Joseph J.; Egge, Kari; Fernandez, Soledad and Hennigan, Mary (2007) 'A Field Test of Three LQAS Designs to Assess the Prevalence of Acute Malnutrition', International Journal of Epidemiology 36: 858-64

Dercon, Stefan (2006) 'Vulnerability: A Micro Perspective', in François Bourguignon, Boris Pleskovi and J. van der Gaag (eds), Securing Development in an Unstable World, Washington DC: World Bank: 115-45

Dias, B. et al. (2010) Using Mobile Phones and Open Source Tools to Empower Social Workers in Tanzania, International Conference on Information and Communication Technologies and Development, Royal Holloway, University of London, 13-16 December

Garrib, A.; Stoops, N.; McKenzie, A.; Dlamini, L.; Govender, T.; Rohde, J. and Herbst, K.
(2008) 'An Evaluation of the District Health Information System in Rural South Africa', South African Medical Journal 98.7: 549-52

Gaventa, J. and Cornwall, A. (2008) 'Power and Knowledge', in P. Reason, and H. Bradbury (eds), The Sage Handbook of Action Research: Participative Inquiry and Practice, London and Thousand Oaks CA: Sage Publications: 172-89

Gillard, H.; Howcroft, D.; Nitev, N. and Richardson, H. (2006) 'A Participatory Approach to Monitoring Slum Conditions: An Example From Ethiopia', Participatory Learning and Action 54: 58-66

Guijt, I. and Cornwall, A. (1995) 'Critical Reflections on the Practice of PRA', PLA Notes 24: $2-7$

Holzmann, Robert and Jørgensen, Steen (2000) Social Risk Management: A New Conceptual Framework for Social Protection and Beyond, Social Protection Discussion Paper 6, Social Protection Unit, Human Development Network, World Bank, http://siteresources.worldbank.org/ SOCIALPROTECTION/Resources/SP-

Discussion-papers/Social-Risk-ManagementDP/0006.pdf (accessed 13 January 2013)

Hoshaw-Woodard, Stacy (2001) Description and Comparison of the Methods of Cluster Sampling and Lot Quality Assurance Sampling to Assess Immunization Coverage, WHO, www.who.int/ vaccines-documents/DocsPDF01/www592.pdf (accessed 13 January 2013)

Hutton, Guy and Tanner, Marcel (2004) 'The Sector-wide Approach: A Blessing for Public Health?', Bulletin of the World Health Organization 82.12: 893-4, www.scielosp.org/pdf/bwho/ v82n12/v82n12a03.pdf (accessed 13 January 2013)

Jonsson, U.; Pelletier, D. and Shrimpton, R. (1998) A UNICEF Nutrition Information Strategy: Improving Decision-making at Household, Community and National Levels, UNICEF Staff Working Paper, New York: UNICEF

Kennedy, J.; Ashmore, J.; Babister, E. and Kelman, I. (2008) 'The Meaning of "Build Back Better": Evidence from Post-Tsunami Aceh and Sri Lanka', Journal of Contingencies and Crisis Management 16.1: 24-36

Lemeshow, S. and Robinson, D. (1985) 'Surveys to Measure Programme Coverage and Impact: A Review of the Methodology used by the Expanded Programme on Immunization', World Health Statistics Quarterly 38.1: 65-75

Lippeveld, Theo (2001) 'Routine Health Information Systems: The Glue of a Unified 
Health System', keynote address at RHINO Workshop on Issues and Innovation in Routine Health Information in Developing Countries, Potomac MD, USA, 14-16 March

Malena, C.; Foster, R. and Singh, J. (2004) Social Accountability: An Introduction to the Concept and Emerging Practice, Social Development Papers 76, Participation and Civic Engagement Group

Management Sciences for Health (2010) Sentinel Site-Based Pilot Active Surveillance Pharmacovigilance in the Vietnam ART Program, USAID, http://pdf.usaid.gov/pdf_docs/PNADU429.pdf (accessed 13 January 2013)

McGee, R. and Gaventa, J. (2010) Synthesis Report: Review of Impact and Effectiveness of Transparency and Accountability Initiatives, London: Transparency and Accountability Initiative MEASURE DHS (2011) DHS History, www.measuredhs.com/aboutdhs/history.cfm (accessed 18 August 2011)

Morduch, Jonathan (1994) 'Poverty and Vulnerability', American Economic Review 84.2: 221-25

Mukherjee, N.; Wartono, D. and Robiarto, A. (2011) Managing the Flow of Monitoring Information to Improve Rural Sanitation in East Java, Working Paper, Global Scaling Up Rural Sanitation, Water and Sanitation Program Myatt, Mark; Feleke, Teshome; Sadler, Kate and Collins, Steve (2005) 'Field Trial of a Survey Method for Estimating the Coverage of Selective Feeding Programmes', Bulletin of the World Health Organization 83.1: 20-6, www.who.int/bulletin/volumes/83/1/ 20arabic.pdf (accessed 13 January 2013)

Park, P.; Brydon-Miller, M.; Hall, B. and Jackson, T. (eds) (1993) Voices of Change: Participatory Research in the United States and Canada, Westport CT: Bergin \& Garvey Prudhon, Claudine and Spiegel, Paul B. (2007)

'A Review of Methodology and Analysis of Nutrition and Mortality Surveys Conducted in Humanitarian Emergencies from October 1993 to April 2004', Emerging Themes in Epidemiology 4, www.ete-online.com/content/pdf/1742-7622-410.pdf (accessed 13 January 2013)

Reyes, C. and Due, E. (2009) Fighting Poverty with Facts: Community Based Monitoring Systems, Ottawa, Canada: International Development Research Centre

Rhoda, Dale A.; Fernandez, Soledad A.; Fitch, David J. and Lemeshow, Stanley (2010) 'LQAS: User Beware', International Journal of Epidemiology 39: 60-8
Robertson, Susan E. and Valadez, Joseph J. (2006) 'Global Review of Health Care Surveys using Lot Quality Assurance Sampling (LQAS), 1984-2004', Social Science and Medicine 63: 1648-60

Sabates-Wheeler, R.; Butters, S. and Greeley, M. (2010) 'Context-specific and Project-induced Risk: Designing Projects for Promoting Resilient Livelihoods', IDS Bulletin 41.6: 96-104 Sander, J.I.; Bell, P.J. and Rice, S.D. (2005) 'MIS Sustainability in Sub-Saharan Africa: Three Case Studies from The Gambia', International Journal of Education and Development using Information and Communication Technology (IJEDICT) 1.3: 135-59

Sankoh, O.A. and Binka, F. (2005) 'INDEPTH Network: Generating Empirical Population and Health Data in Resource-constrained Countries in the Developing World', in H. Becher and B. Kouyate (eds), Health Research in Developing Countries, Berlin, Heidelberg: Springer Verlag

Schellenberg, Joanna; Armstrong, R.M.; Taghreed, Adam; Hassan, Mshinda et al. (2004) 'Effectiveness and Cost of Facilitybased Integrated Management of Childhood Illness (IMCI) in Tanzania', The Lancet 364: 1583-94

Scoones, I. (1998) Sustainable Rural Livelihoods: A Framework for Analysis, IDS Working Paper 72, Brighton: IDS

Seebregts, Christopher, J.; Zwarenstein, Merrick; Mathews, Catherine et al. (2009) 'Handheld Computers for Survey and Trial Data Collection in Resource-Poor Settings: Development and Evaluation of PDACT, a Palm ${ }^{\text {TM }}$ Pilot Interviewing System', International Journal of Medical Informatics 78: 721-31

Sen, A. (1981) Poverty and Famines: An Essay on Entitlement and Deprivation, Oxford: Clarendon Press

Shaw, V. (2005) 'Health Information System Reform in South Africa: Developing an Essential Data Set', Bulletin of the World Health Organization 83.8: 632-9

Shoham, Jeremy; Watson, Fiona and Dolan, Carmel (2001) The Use of Nutritional Indicators in Surveillance Systems: Report to DFID, London: Overseas Development Institute

SMART (2005) Measuring Mortality, Nutritional Status, and Food Security in Crisis Situations: SMART Methodology, The SMART Initiative, www.smartindicators.org/SMART_Protocol_01 -27-05.pdf (accessed 13 January 2013) 
Sserwanga, Asadu; Harris, Jamal C.; Kigozi, Ruth; Menon, Manoj et al. (2011) 'Improved Malaria Case Management through the Implementation of a Health Facility-Based Sentinel Site Surveillance System in Uganda', PLoS ONE 6.1: 1-9

Swift, J. (1989) 'Why are Rural People Vulnerable to Famine?', IDS Bulletin 20.2: 8-15

Teller, Charles (2008) Technical Assessment of Data Quality and Information Use of the Malawi Integrated Nutrition and Food Security Surveillance System: Developing the System's Capacity and Importance for Nutrition Planning, Intervention, Monitoring and Evaluation, Rome: Food and Agriculture Organization (FAO) www.foodsec.org/fileadmin/user_upload/eufaofsi4dm/docs/malawi_food_info_system.pdf (accessed 4 March 2013)

Tomlinson, Mark; Solomon, Wesley; Singh, Yages et al. (2009) 'The Use of Mobile Phones as a Data Collection Tool: A Report from a Household Survey in South Africa', $B M C$ Medical Informatics and Decision Making 9.51, www.biomedcentral.com/1472-6947/9/51 (accessed 13 January 2013)

Traxler, John and Dearden, Philip (2005) The Potential for Using SMS to Support Learning and Organisation in Sub-Saharan Africa, London: Department for International Development Turner, Anthony G.; Magnani, Robert J. and Shuaib, Muhammad (1996) 'A Not Quite as Quick but Much Cleaner Alternative to the Expanded Programme on Immunization (EPI) Cluster Survey Design', International Journal of Epidemiology 25.1: 198-203

UNICEF (2011) Statistics and Monitoring. Multiple Indicator Cluster Survey (MICS), www.unicef.org/statistics/index_24302.html (accessed 18 August 2011)

Wall, I. (2006) The Right to Know: The Challenge of Public Information and Accountability in Aceh and Sri Lanka, Office of the UN Secretary's General Special Envoy for Tsunami, http://mhpss.net/wp-content/uploads/groupdocuments/44/1309456377-The_Right_to_ Know.pdf (accessed 13 January 2013) 